\title{
A importância da sanidade e do bem-estar na prevenção de doenças parasitárias, infectocontagiosas, congênitas e nutricionais em coelhos
}

\author{
The importance of health and well-being in preventing parasitic, \\ infectious, congenital and nutritional diseases in rabbits
}

\author{
Rebeca Garcia Lemes ${ }^{1}$, Fernando Henrique Pimenta de Moura ${ }^{1}$, Gabriela do Vale Pombo Guarnieri ${ }^{2}$ \\ ${ }^{1}$ Acadêmicos em Zootecnia do Centro Universitário da Fundação Educacional de Barretos, Unifeb, Barretos, SP. \\ ${ }^{2}$ Professora do Centro Universitário da Fundação Educacional de Barretos, Unifeb, Barretos, SP.
}

\begin{abstract}
RESUMO
A cunicultura é uma atividade que está em crescimento no país, em razão das diversas vantagens que a produção de coelhos detém quando comparada a outras atividades do segmento pecuarista. Para maximizar os índices de produtividade, é de extrema importância a adoção de práticas racionais no manejo sanitário, nutricional e reprodutivo. Sendo assim, torna-se necessário o conhecimento das enfermidades que acometem os coelhos para que se possa realizar um plano preventivo a fim de ser implantado no manejo do sistema de produção. Diante do exposto, o objetivo deste trabalho foi realizar uma revisão de literatura sobre as doenças parasitárias, infectocontagiosas, congênitas e nutricionais que ocorrem na cunicultura.
\end{abstract}

Palavras-chave: criação de coelhos; enfermidades dos coelhos; manejo sanitário; produção animal.

\begin{abstract}
Rabbit farming is an activity that is growing in the country, this factor has been observed due to the several advantages that the production of rabbits holds when compared to other activities in the livestock segment. To maximize productivity rates, it is extremely important to adopt rational practices in sanitary, nutritional and reproductive management. Thus, it is necessary to know the diseases that affect rabbits so that a preventive plan can be made in order to be implemented in the management of the adopted production system. Given the above, the objective of this study was to make a brief report of the parasitic, infectious, congenital and nutritional diseases that affect rabbits.
\end{abstract}

Keywords: Rabbit breeding; rabbit diseases; sanitary management; animal husbandry.

Autor para correspondência: Rebeca Garcia Lemes. Fundação Educacional de Barretos, E-mail: rebecaglemes@hotmail.com (17) 99251-4834

Recebido para publicação: 04/03/2020

Aceito para publicação: 14/08/2020

https://doi.org/10.4322/1980-0029.152020 


\section{Introdução}

A cunicultura é uma atividade estratégica, econômica e sustentável que se encontra em crescimento em algumas regiões do país. Além de possuir clima favorável para a exploração racional dos coelhos, o Brasil conta com uma vasta disponibilidade de área e insumos que podem ser destinados para o desenvolvimento da cunicultura com elevada produtividade. A produção de coelhos possibilita a geração de diversos produtos finais, como a carne, a pele, os pelos e também os pets, que são uma parcela expressiva e lucrativa do mercado cunícula (Machado, 2012). Paralela a outras criações, a atividade cunícula não expressa uma elevada representatividade; isso ocorre porque a grande maioria dos produtores tem a cunicultura como uma atividade extra, sendo uma fonte de renda secundária (Bonamigo et al., 2017). Algumas das vantagens oferecidas pela cunicultura são alta prolificidade, utilização de espaços menores, facilidade no manejo sem muito esforço físico, investimento inicial de baixo custo e ainda ser uma atividade sustentável por causa da baixa produção de dejetos com possibilidade de reutilização, como biofertilizante, e do aproveitamento dos subprodutos, por exemplo, o sangue, que pode ser aplicado na biotecnologia por meio da produção de soro; o cérebro, que é fonte de obtenção da tromboplastina; a pele, que pode ser utilizada na confecção de roupas; o couro, que é amplamente utilizado na produção de acessórios e vestimentas; e as vísceras, que são usadas na fabricação de ingredientes para formulação de ração para animais (Valentim et al., 2018). As decisões a serem tomadas para dar início à construção de um coelhário levam em consideração a morfologia e a fisiologia do animal, de acordo com o objetivo da criação. A verificação da genética do animal garante uma melhor seleção, prevenindo o surgimento de coelhos com doenças congênitas. Ainda, a nutrição deve ser garantida em toda a fase de vida, advinda de produtos de confiança, livres de micotoxinas e armazenadas de forma correta em local limpo e longe de umidade. Para a garantia de bons índices assegurando rentabilidade e redução de riscos, deve-se realizar um manejo eficiente, de tal forma que garanta o bem-estar dos animais, possibilitando que eles expressem seu potencial ao máximo de forma saudável e evitando possíveis distúrbios comportamentais e enfermidades. As instalações devem proporcionar comodidade e conforto para os coelhos, garantindo boas condições ambientais, sanitárias e nutricionais. O tipo de instalação a ser inserida depende do sistema de produção a ser escolhido, podendo ser extensivo, na qual os animais são criados soltos, semi-intensivo, que possibilita que os animais sejam criados soltos em determinada hora do dia, e intensivo, com animais completamente confinados (Mello \& Silva, 2003; Del Campo et al., 2010; Pires, 2012; Silva, 2019).

Em sistemas de criações intensivas, é comum a utilização de gaiolas, pois elas promovem uma maior taxa de lotação. Contudo, embora pareça ser vantajosa a adoção dessa medida no coelhário, altas densidades por gaiola possibilitam a disseminação de doenças e afetam a performance dos animais, gerando desconforto em virtude do ambiente em que eles estão alojados (Maertens \& De Groote, 1984; Aubret \& Duperray, 1993; Araújo et al., 2015). Nessas circunstâncias, os custos com medicamentos se elevam. Além disso, há o comprometimento de quatro dos cinco domínios que contemplam o bem-estar animal (o ambiente, a sanidade, o comportamento do animal e o estado mental).

São diversos os fatores que determinam o bemestar dos animais do coelhário, podendo impactar no seu dia a dia, influenciando negativamente a curto, médio e longo prazo. Esses fatores podem ser mais bem compreendidos se visualizados dentro dos cinco domínios do bem-estar animal: nutrição (privação de alimento, privação de água, desnutrição), ambiente (frio, calor, espaço insuficiente, problemas de manejo), saúde (doenças, ferimentos, comprometimento funcional), comportamento (restrições comportamentais naturais da espécie e nas interações entre os indivíduos) e estado mental (fome, sede, dor, medo, debilidade, solidão, ansiedade, frustração, depressão e desesperança) (Mellor \& Reid, 1994).

Um dos grandes entraves da cunicultura é a alta taxa de mortalidade, tendo como principais causas a nutrição das matrizes, o ambiente em que os coelhos estão inseridos e a condução do manejo realizado pelos colaboradores (Machado, 2014).

Para maximizar os índices de produtividade, é de extrema importância a adoção de práticas racionais no manejo sanitário, nutricional e reprodutivo. Por meio da condução correta da atividade, é proporcionado aos animais um ótimo status de saúde, um ambiente seguro e limpo, o fornecimento de alimento e água de qualidade, livre 
de agentes contaminantes, e, consequentemente, uma rotina que não provoque estresse aos animais.

Além do conhecimento das doenças, entender o comportamento dos animais é uma ferramenta que auxilia na tomada de decisão para elaboração do plano preventivo. Entre os comportamentos apresentados pelos animais enfermos se destacam: olhar apático; orelhas caídas; pouca movimentação, permanecendo mais tempo encolhidos nos cantos das gaiolas; pelos opacos e arrepiados; pele com feridas ou não, dependendo da origem da doença; inapetência e até mesmo diarreias.

Coelhos enfermos têm sua produtividade, consumo e desenvolvimento reduzidos; logo, seu crescimento é comprometido, tendo seu peso ideal atingido de forma tardia quando comparados a animais sadios. Aliados a esses fatores, os gastos com medicamentos e mão de obra se elevam, onerando os custos de produção (Silva, 2019).

Sendo assim, é importante o conhecimento das enfermidades que acometem os coelhos para que se possa realizar um plano preventivo a fim de ser implantado no manejo do sistema de produção. Diante do exposto, o objetivo deste trabalho foi realizar uma revisão de literatura sobre as doenças parasitárias, infectocontagiosas, congênitas e nutricionais que ocorrem nos coelhos, bem como apresentar um plano preventivo de enfermidades que ocasionam prejuízos econômicos à cunicultura.

\section{Doenças parasitárias}

Os parasitas são organismos que se associam a um hospedeiro e retiram seus recursos necessários para sobreviver. Eles são classificados em ácaros, protozoários e vermes, denominados também como endoparasitas (Rodrigues, 2007; Falcone et al., 2017).

\subsection{Sarna}

É provocada por ácaros, sendo o Sarcoptes scabiei o agente etiológico causador da sarna do corpo, cuja ação contaminante também atinge os seres humanos, caracterizando-a, assim, como uma zoonose (Papeschi, 2010). Já o Psoroptes cuniculi ocasiona a sarna das orelhas.

Geralmente é comum observar os animais com coceira e secreção (Luciano, 2008). As lesões têm início na cabeça, progredindo para o resto do corpo; isso ocorre porque esfregam a cabeça com frequência. Além disso, torna a pele seca, sem pelos, dura e escamosa (Simões, 2011). Quando acometidos pela sarna das orelhas, é possível visualizar crostas escuras na região, provocando incômodo e agitação nos animais.

\subsection{Verminose}

A principal verminose é a Taenia pisiformis, um helminto que possui ciclo heteroxeno, ou seja, precisa de dois hospedeiros para completar seu ciclo de vida. O primeiro estágio é larval, na qual acomete os coelhos por meio da ingestão dos ovos via alimentos e/ou água contaminadas. O segundo estágio, na qual a Taenia spp. é adulta, ocorre nos hospedeiros definitivos, em outras espécies de animais (Contreiro, 2014).

Coelhos infectados passam mais tempo deitados e dedicam menos tempo aos cuidados de higiene. Os animais, quando abatidos, também apresentam lesões nos órgãos internos, caso não tenha sido feito o tratamento recomendado (Contreiro, 2014).

\subsection{Toxoplasmose}

É uma zoonose, distribuída mundialmente, causada pelo protozoário Toxoplasma gondii. A infecção nos coelhos ocorre por meio da ingestão de oócitos presentes em alimentos ou água contaminada.

Sua ocorrência geralmente é assintomática, no entanto, com o aumento da virulência, causa infecção, gerando febre, convulsões, paralisia de membros e morte em poucos dias (Lima, 2015).

\subsection{Coccidiose}

É uma infecção provocada por protozoários do gênero Eimeria ssp., cuja ação parasitária ocorre no fígado, e Cryptosporidium spp., no intestino.

O contágio pelos animais ocorre via oral pela ingestão de oocistos. Os sinais clínicos observados são diarreia aguda, principalmente em filhotes de criações intensivas, redução da ingestão de alimentos e dificuldade da digestão de lipídeos presentes na dieta (Almeida et al., 2006; Fekete \& Kellems, 2007).

Coelhos com coccidiose diminuem significativamente a ingestão voluntária de alimentos e a digestibilidade das gorduras.

\section{Doenças infectocontagiosas}

As doenças infectocontagiosas, conhecidas também como infecciosas, são aquelas que possuem os microrganismos como agentes causadores, por 
exemplo, vírus, fungos e bactérias. Eles podem estar presentes no próprio organismo dos animais, estabelecendo uma relação de comensalismo, e, em casos de desequilíbrio do sistema imune, provocar alguma patologia. Há também a possibilidade de o agente etiológico estar disperso no ambiente; logo, em más condições sanitárias, os animais entram em contato por meio de alimentos, água e também pelo contato direto com veículos (Rosell \& Madrid, 2002).

\subsection{Doenças virais}

São doenças provocadas por vírus, acometendo todos os tecidos e órgãos dos animais, apropriando-se das células e se replicando, o que torna difícil sua eliminação. Atualmente, já foram desenvolvidos agentes combatentes para as doenças virais, as vacinas, que são eficientes, e os antibióticos, que agem como um meio de aumentar a resistência ao agente viral (Falcone et al., 2017).

\subsubsection{Mixomatose}

É uma doença com alto índice de virulência e letal, não possuindo cura. É transmitida por insetos como moscas, mosquitos e pulgas, com possível transmissão horizontal de um animal para outro (Nunes, 2016). Os sinais clínicos iniciais são nódulos em torno dos olhos, com seu desenvolvimento. Há o surgimento de úlceras, conjuntivite, infecções subcutâneas, tumores na face e orelha (Catroxo et al., 2009).

\subsubsection{Raiva}

É uma doença existente desde os tempos mais antigos, classificada como uma zoonose (Babboni \& Modolo, 2011). Seus sinais clínicos podem se apresentar de forma variada, sendo os mais comuns: ausência de apetite, modificação comportamental, apatia, falta de coordenação motora, possível paralisia motora, salivação excessiva e morte por paralisia dos órgãos respiratórios (Batista et al., 2007).

\subsubsection{Doença Hemorrágica do Coelho}

Essa doença provoca um alto índice de mortalidade no coelhário e ainda eleva a possibilidade de o animal ser acometido pela hepatite necrótica fulminante e diátese hemorrágica (Marques, 2014). Até então a doença está categorizada como "nunca registrada no País e erradicada” (Brasil, 2013).

\subsection{Doenças fúngicas}

Fungos são organismos eucariontes que habitam locais úmidos e quentes. Eles estabelecem uma relação de parasitismo com os coelhos, provocando desde doenças simples até mesmo a morte (Falcone et al., 2017). Embora sejam pequenos, os fungos podem causar grandes prejuízos econômicos ao produtor.

\subsubsection{Encefalite cunícula}

É uma zoonose portadora do fungo Encephalitozoon cuniculi. Este agente tende a preferir hospedar os coelhos, ocorrendo transmissão via horizontal ou vertical. Pode causar inflamação no miocárdio, no cérebro e na placenta, aborto, catarata, glaucoma e morte (Patrício, 2014).

\subsubsection{Dermatofitose}

A doença ocorre em razão do erro de manejo sanitário e é causada por duas espécies de fungos: o Trichophyton spp e Microsporum spp. Ela é caracterizada como uma zoonose e causa lesões por todo corpo dos coelhos, sendo distribuída nas regiões do focinho, orelhas e pernas (Luciano, 2008). Os sinais clínicos são decorrentes da queda de pelo, lesões avermelhadas, ásperas e secas (Santos, 1975).

\subsection{Doenças bacterianas}

As bactérias são seres unicelulares e procariontes, podendo ser encontradas dispersas no meio ambiente, colonizando todo e qualquer meio interno e/ou externo de plantas e animais, agindo de forma benéfica ou causando malefícios quando expostos ao estresse, o que acarreta desequilíbrios no hospedeiro (Falcone, et al., 2017).

\subsubsection{Pasteurelose}

É considerada como uma das principais doenças na cunicultura por ocasionar perdas significativas. Além de ser caracterizada como uma zoonose (Kanayama et al., 2011; Makino \& Nakaghi, 2008; Falcone et al., 2017), a pasteurelose é provocada pela bactéria Pasteurella multocida, que se encontra geralmente no trato respiratório superior e digestivo dos coelhos. A doença tem início em situações de estresse, principalmente quando o sistema imune se encontra em um estado mais frágil, como na prenhez, lactação, situações de manejo inadequado ou frio excessivo, 
provocando problemas respiratórios (Makino \& Nakaghi, 2008).

Além do estado fisiológico, a alta densidade populacional por gaiola é outro fator que favorece o aparecimento da infecção. Os sinais clínicos mais comuns são coriza, espirros, febre, abcessos na pele e no pulmão e pneumonia (Makino \& Nakaghi, 2008).

\subsubsection{Mastite}

A mastite é um quadro de infecção e inflamação das glândulas mamárias que pode ser provocada em coelhos por duas espécies de bactérias: a Staphylococcus aureus ou a Pasteurella multocida (Rebelo, 2017; Silva et al., 2017).

Os sinais clínicos mais comuns são a dermatite exsudativa em coelhas lactantes. Embora não seja considerada uma doença de alta gravidade, é de extrema importância a adoção de medidas profiláticas a fim de evitar o sofrimento dos animais por causa do quadro inflamatório (Falcone et al., 2017).

\subsubsection{Salmonelose}

A incidência desta zoonose em coelhos ocorre, principalmente, em criações intensivas, em geral naquelas que não praticam um bom manejo sanitário. A Salmonella sp. está presente no trato gastrointestinal dos próprios animais e no desenvolvimento da salmonelose, levando os coelhos a apresentar diarreia, febre, queda de peso e apatia (Falcone et al., 2017).

Vale ressaltar que a não adoção de práticas higiênico-sanitárias no processo de abate de coelhos pode acarretar contaminação da carcaça pela Salmonella sp., inviabilizando, assim, o seu consumo, por se tornar uma fonte de infecção para o consumidor final (Coelho, 2010).

\subsubsection{Tularemia}

A tularemia é uma patologia caracterizada como zoonose, possuindo como agente causador a Francisella tularensis. Nem sempre essa doença vem acompanhada de sintomas, no entanto, quando ocorrem, pode-se observar nos animais depressão severa e até mesmo a morte de animais extremamente sensíveis. Até o presente momento não foram encontrados registros dessa doença no Brasil (Coelho, 2010; Falcone, et al., 2017).

\subsubsection{Dermatite úmida}

A dermatite úmida é uma enfermidade comum em coelhos. Os maiores índices são nos meses mais quentes do ano (Falcone et al., 2017), quando os coelhos aumentam a ingestão de água na tentativa de diminuir sua temperatura corporal interna. Geralmente essa enfermidade se dá em fêmeas, pois, na região ventral, há uma prega que umedece naturalmente a pele e, ao entrar em contato com as fezes dos animais, adquire o agente etiológico, a bactéria Pseudomonas aeruginosa (Makino et al., 2005).

Além da região ventral, essa dermatite pode ocorrer em outras regiões do corpo dos animais, como aquelas que entram em contato com a umidade de superfícies quando os coelhos se deitam (Makino et al., 2005; Falcone et al., 2017).

\section{Doenças congênitas}

São de princípio genético, tendo como ocorrência a mutação de forma esporádica ou por meio de fatores externos, tais como radiação e alimentos e água contaminados, além de genes autossômicos causados pela endogamia (Schiere \& Corstiaensen, 2008).

\subsection{Displasia coxofemoral}

Também conhecida como "pernas abertas", a displasia coxofemoral é considerada uma doença degenerativa por alterar o funcionamento de tecidos e órgãos, sendo um erro de aprumo e falta de mobilidade nas pernas. Ela causa extremo desconforto e dificulta a cecotrofagia, provocando sérios problemas nutricionais nos animais. É possível visualizar essa doença ao desmamar um coelho jovem de 40-60 dias de vida (Trapp et al., 2010).

\subsection{Prognatismo}

Decorre por causa de alguns coelhos possuírem problemas de oclusão nos dentes, não possibilitando o desgaste destes, ocorrendo, consequentemente, o crescimento desalinhado, o que impede que os animais se alimentem; com isso, ocorre anorexia e debilidade extrema (Souza et al., 2016).

\section{Doenças nutricionais}

As doenças nutricionais são oriundas do manejo nutricional incorreto. A formulação de dietas é de total responsabilidade do zootecnista, por isso é de extrema importância 
que o produtor consulte esse profissional para o desenvolvimento de uma dieta específica para as necessidades dos animais de acordo com a categoria, idade, sexo, fase produtiva (lactação, prenhes, reprodução, entre outras) e sistema de produção implantado. Dietas que não são formuladas por esses profissionais podem ser duvidosas e, com o desbalanço nutricional, mineral e energético da dieta, podem provocar nos coelhos sérios problemas. Para se evitar essas doenças, é necessário conhecer as exigências nutricionais dos animais em cada fase de produção e formular as dietas de forma correta. Os déficits vitamínicos podem ser ajustados por meio do uso de premix na ração, e é recomendado que não sejam usadas rações fareladas, pois, além de ocorrer seleção, há perdas e não é realizado o desgaste dos dentes dos animais como é feito pela ração peletizada (Klinger et al., 2013).

De modo geral, os coelhos têm a necessidade obrigatória de ingerir no mínimo $8 \%$ de fibra bruta em suas dietas, sendo recomendado $16 \%$, porém o fornecimento à vontade de volumoso não causa nenhum malefício aos animais. Por serem animais herbívoros, é ideal o consumo de alimentos volumosos à vontade, assim como em ruminantes, podendo ser utilizado o feno de alfafa, que é uma ótima alternativa para suprir algum tipo de déficit mineral.

Segundo Blas \& Wiseman (2010), os níveis baixos de fibra reduzem a velocidade da taxa de passagem da digesta e pode causa a morte dos animais Por isso, o fornecimento de uma dieta bem formulada evita possíveis doenças, prejuízos e perdas econômicas.

\subsection{Hipocalcemia ou Febre vitular}

É uma doença causada pelo déficit de cálcio ou desequilíbrio de minerais na dieta, ocorrendo erros no metabolismo endócrino-mineral. Portanto, os coelhos necessitam do cálcio, que é metabolizado e absorvido no intestino, e seus excessos são excretados pelos rins (Lopes, 2010). Essa doença está mais propensa a acometer coelhas lactantes, pois é a categoria que mais necessita de cálcio para manter a gestação e produzir leite. Sua deficiência acarreta falta de apetite, espasmos musculares, queda ou inibição da produção de leite, paralisia muscular ou até a morte (Falcone et al., 2017).

\subsection{Tricofagia}

Tricofagia é o nome dado ao ato que os animais realizam de automutilação, arrancando os próprios pelos e os de outros coelhos para ingestão. Os coelhos adquirem esse comportamento por causa de estresse, transtornos comportamentais, dominância, espaços pequenos e mal planejados e déficit de nutrientes na dieta. A causa mais comum seria o déficit nutricional, proveniente de uma dieta mal formulada, provocando o estresse e as perdas na produtividade dos animais (Falcone et al., 2017).

Geralmente, quando há uma falta de nutriente, principalmente a fibra e a proteína na alimentação, pode ocorrer a tricofagia, sendo menos comum sua ocorrência em razão de carência de minerais como o zinco.

\section{Doenças provocadas por erro de manejo}

\subsection{Calosidade ou Pododermatite, ou Bumblefoot}

A calosidade não é uma doença, e sim um ferimento que acomete as solas das patas dos animais por causa da pressão contínua sobre elas. No entanto, ela pode se tornar uma infecção se houver demora no diagnóstico e tratamento (Papeschi, 2010).

\subsection{Calcificação nas artérias}

A calcinação das artérias é originada por erros no manejo nutricional dos animais. O desbalanço de nutrientes e minerais pode gerar essa doença. Geralmente esse quadro ocorre quando são administradas na dieta grandes quantidades de vitamina $\mathrm{D}$, que é um agente fixador de cálcio (Liberman et al., 2013).

\section{Manejo sanitário visando à prevenção de doenças}

Realizar o controle zootécnico dos animais é sinal de uma produção confiável, uma vez que o produtor possui os dados referentes a cada animal. Por isso, cumprir o tratamento de doenças que acometam o coelhário pode se tornar mais fácil. Além disso, efetuar a prevenção e o tratamento de doenças é de grande seriedade, visto que animais doentes se tornam fonte de infecção para outros animais, acarretando diretamente prejuízos econômicos pela diminuição da produtividade. 
De modo geral, a saúde dos animais envolve fatores associados a enfermidades, saúde pública (zoonoses) e controle de riscos da cadeia produtiva. Assegurar uma boa condição na criação de coelhos garante a oferta de alimentos livres de contaminação e o bem-estar único (Brasil, 2015). Para um manejo sanitário de sucesso, é de extrema importância a atuação de profissionais capacitados, como o zootecnista, que se dedica na prevenção das doenças, na higiene das instalações e equipamentos, no fornecimento de água de qualidade, na promoção de um status nutricional adequado, respeitando a categoria e a fisiologia dos animais, bem como o médico-veterinário, que atua no diagnóstico e tratamento de animais enfermos.

As doenças que acometem os coelhos não ocorrem sempre por causa de um fator isolado. Em regra, elas têm início em razão de multifatores que possuem probabilidade estatística de modificar a saúde (Thrusfield, 1995), como os animais, o alojamento, a alimentação, o manejo e a microbiologia da exploração (Rosell \& Madrid, 2002).

É sabido que animais jovens, como os láparos, os mais velhos e aqueles em estado fisiológico mais sensível, como matrizes recém-paridas, são mais predispostos a ser acometidos por doenças; assim, o controle dos outros fatores de risco devem ser controlados.

As instalações devem ser mantidas sempre limpas, higienizadas e ventiladas para que haja a renovação do ar, com controle de temperatura indicado para as diferentes fases de vida dos animais dentro do coelhário, proporcionando, assim, um conforto térmico, respeitando a variação de 15 a $20^{\circ} \mathrm{C}$ para animais mais velhos e jovens, respectivamente. Os equipamentos também devem se manter limpos (bebedouros, comedouros) e funcionais.

A alimentação deve atender às exigências nutricionais dos coelhos, e os ingredientes devem respeitar os limites de adição em uma dieta, além de serem livres de agentes contaminantes e suas excreções, como as micotoxinas que são liberadas por fungos.

O manejo de animais de forma tranquila é crucial para que os coelhos se mantenham saudáveis. Manejos estressantes afetam diretamente o sistema imune deles, tornando-os mais susceptíveis a doenças, sejam elas de origem viral, bacteriana, fúngica ou nutricional. Ademais, o estresse compromete o bem-estar dos coelhos, podendo alterar a expressão do comportamento habitual e provocando também agressividade.

Vale ressaltar também que a introdução de animais novos no criadouro não deve ser feita de qualquer maneira. É importante realizar a quarentena antes de acomodá-los dentro das instalações junto de outros animais. Mesmo que a aquisição tenha sido feita em locais renomados e seguros, o ambiente possui microrganismos que podem ser levados por um animal portador, por isso a quarentena é um manejo que evita a possível disseminação de agentes causadores de doenças para o coelhário local.

Ainda sobre a microbiologia do criadouro, tão importante quanto os cuidados ao introduzir animais novos, após a saída de animais para o abate e futura reposição, o vazio sanitário da instalação é fundamental para que os coelhos repostos não sejam acometidos por enfermidades que possam ter ocorrido no lote anterior.

Além da quarentena e do vazio sanitário, o controle de roedores e insetos é um ponto importante a ser seguido. Quando praticado corretamente, evita a disseminação de doenças, pois esses veículos são portadores de diversos microrganismos que podem provocar patologias no coelhário, não somente pelo contato direto, como a picada dos animais pelos insetos, mas também pela contaminação de água ou ração por causa de excreções dos roedores, como a urina, ou a decomposição deles, quando se acidentam e morrem dentro das instalações.

De modo geral, as instalações destinadas à armazenagem e manipulação de dejetos, as áreas de compostagem e as fossas sépticas deverão ser implantadas e manipuladas com todo o cuidado necessário a fim de prevenir a contaminação do solo e lençóis freáticos (Brasil, 2011).

\subsection{Doenças parasitárias}

A ocorrência de doenças parasitárias em coelhário é elevada quando há falta de higiene, má ventilação e umidificação excessiva das instalações. A profilaxia para as doenças de origem parasitária é baseada nas boas práticas de manejo sanitário:

1) Evitar os fatores agravantes mencionados.

2) Limpar e pulverizar as instalações com sarnicida não tóxico para coelhos.

3) Aplicar cal viva ou superfosfato de cálcio nas fossas e também nas instalações quando os 
coelhos forem acometidos pela coccidiose para impedir a maturação dos oócitos.

4) Não permitir o contato de gatos e cães com os coelhos.

5) Eliminar animais doentes por toxoplasmose.

6) Realizar a evermifugação dos animais.

\subsection{Doenças infectocontagiosas}

Manter um status higiênico-sanitário do coelhário é a melhor maneira de evitar a ação contaminante dos microrganismos, uma vez que eles se encontram dispersos em diversos ambientes, seja ele terrestre, aquático ou aéreo.

\subsubsection{Doenças virais}

Algumas doenças virais não possuem cura, como a mixomatose e a doença hemorrágica do coelho. Diante disso, preveni-las é a melhor solução.

1) Seguir as recomendações mencionadas anteriormente de maneira a manter as instalações limpas, higienizadas e seguras.

2) Realizar a vacinação preventiva dos coelhos em regiões onde houve relatos de surtos de mixomatose, bem como a revacinação de seis em seis meses.

3) Realizar a eutanásia dos coelhos acometidos pela mixomatose e, posteriormente, incinerar os corpos.

4) Sacrificar e incinerar coelhos acometidos pela raiva, pois não há um tratamento formal. A vacinação é recomendada apenas para coelhos de companhia, por serem pouco frequentes em criadouros.

5) Vacinar os animais contra a doença hemorrágica (embora não seja obrigatório no Brasil). No caso de ocorrência no criadouro, são indicadas a eutanásia e a incineração dos corpos.

6) Manter as instalações e equipamentos sempre limpos.

\subsubsection{Doenças fúngicas}

1) Eutanasiar coelhos acometidos pela encefalite cunícula para não contaminar o restante do plantel.

2) Evitar o contato das gaiolas com o solo.

3) Controlar a umidade da instalação.
4) Manter as instalações e os equipamentos limpos e higienizados.

\subsubsection{Doenças bacterianas}

1) Evitar a umidade excessiva das instalações.

2) Em criações extensivas ou semi-intensivas, deve-se verificar se há poças de água e lama, pois o contato da umidade com o ventre dos coelhos pode provocar a dermatite úmida.

3) Manter uma alta densidade de coelhos/gaiola.

4) Evitar o contato de cães e gatos, pois podem ser portadores de microrganismos patógenos.

5) Transferir láparos em ninhadas com menos de oito para prevenir casos de mastite.

6) Manter o conforto térmico dos animais.

7) Boas práticas higiênico-sanitárias.

\subsection{Doenças nutricionais}

Realizar a formulação de dietas para qualquer espécie animal é uma grande responsabilidade, uma vez que devem ser levados em consideração fatores distintos inerentes à espécie. Sendo assim, consultar um zootecnista é a melhor decisão para que não haja essa problemática em criadouros de coelhos.

1) Consultar um zootecnista.

2) Não utilizar formulação de outros criadores, uma vez que a exigência nutricional dos animais está associada à raça, sexo, idade, categoria, clima do local, fase produtiva e disponibilidade dos ingredientes em cada região.

3) Para diminuir a incidência da tricofagia, além dos fatores nutricionais, fornecer um ambiente tranquilo, calmo e livre de estresse é ponto-chave que auxilia na prevenção desse comportamento.

\subsection{Doenças congênitas}

A fim de evitar a incidência de doenças congênitas no plantel, é importante que o produtor e profissional fiquem atentos quanto à tomada de decisão.

1) Realizar a reposição de reprodutores por coelhos de outros criadores idôneos para 
que não haja consanguinidade e ocorrência de genes deletérios.

2) Eliminar animais que apresentem problemas congênitos e, em hipótese alguma, utilizá-los para reprodução, uma vez que vão transmitir esses problemas genéticos para os láparos.

\subsection{Doenças provocadas por erro de manejo}

A manutenção dos equipamentos e ambiente limpos, higienizados, ventilados, com umidade controlada e seguro para os animais, além do fornecimento de água de qualidade, dietas balanceadas com ingredientes livres de agentes contaminantes, bem como a realização de quarentena, vazio sanitário, controle de insetos e roedores e vacinação de doenças são fatores aliados para um manejo sanitário adequado. No entanto, tão importante quanto esses elementos, a forma como os coelhos são manejados no dia a dia afetará todo o sistema imunológico do animal.

O estresse é um grande vilão da saúde, por isso é importante tomar alguns cuidados para que os animais não tenham seu bem-estar afetado.

1) Realizar a conscientização e capacitação dos funcionários para que eles pratiquem um manejo racional, livre de estresse e agressividade.

2) Utilizar apoio de material macio sobre o piso ou gaiolas para que haja um descanso dos membros dos coelhos a fim de evitar calosidades.

3) Proporcionar conforto térmico aos animais por meio da climatização adequada da instalação.

4) Inserir objetos de enriquecimento ambiental nas gaiolas para proporcionar um entretenimento, diminuindo, assim, os índices de estresse.

\section{Considerações Finais}

Com a presença do zootecnista no coelhário, o manejo nutricional, sanitário e, principalmente, ambiental será conduzido de forma a evitar as diversas doenças que acometem os coelhos, proporcionando bem-estar dos animais e da atividade como um todo. Além disso, é indispensável a presença do médico-veterinário, pois ele é o responsável pelo diagnóstico correto e tratamento das enfermidades.

Estabelecer um manejo higiênico-sanitário e adotar práticas de bem-estar é fundamental para que a cunicultura se torne uma atividade produtiva, sadia e lucrativa.

\section{Referências}

Almeida, A. J., Mayen, F. L., \& De Oliveira, F. C. (2006). Espécies do gênero Eimeria observadas em fezes de coelhos domésticos (Oryctolagus cuniculus) criados no município de Campos dos Goytacazes, Rio de Janeiro, Brasil. Revista Brasileira de Parasitologia Veterinária, 15(4), 163-166.

Araújo, J. P., Marques, R., Pereira, C., Tavares, T., Cantalapiedra, J., \& Cerqueira, J. L. (2015). Influência de diferentes densidades de alojamento na performance produtiva de coelhos em engorda. In Anais do XIX Congresso de Zootecnia-Diversidade na Produção (pp. 284-287). Vila Real: Associação Portuguesa de Engenheiros Zootécnico.

Aubret, J. M., \& Duperray, J. (1993). Effect of cage density on the performance and health of the growing rabbit. Journal of Applied Rabbit Research, 15, 656-660.

Babboni, S. D., \& Modolo, J. R. (2011). Raiva: origem, importância e aspectos históricos. UNOPAR Científica. Ciências Biológicas e da Saúde, 13(Esp.), 349-356.

Batista, H. B. D. C. R., Franco, A. C., \& Roehe, P. M. (2007). Raiva: uma breve revisão. Acta Scientiae Veterinariae, 35(2), 125-144.

Blas, C., \& Wisewan, J. (Eds.). (2010). Nutrition of the Rabbit. Cabi. Recuperado em: 20 de novembro de 2019, de https://books.google. com.br/books?hl=pt-BR\&lr=\&id=r3vUDwAA QBAJ\&oi $=$ fnd \&pg $=$ PR $3 \& d q=$ De + Blas + C. $\% 3$ $\mathrm{B}+$ Wiseman, $+\mathrm{J} .+$ Nutrition + of + the + rabbit. $+\mathrm{N}$ ottingham. + Editora $+\mathrm{CABI},+2010 .+\&$ ots $=$ sic jVbHggP\&sig=w_cYMCJfxzVAZhHVopYLjy $47 \mathrm{hI} \# \mathrm{v}=$ onepage $\& \mathrm{q} \& \mathrm{f}=$ false

Bonamigo, A., Duarte, C., Winck, C. A., \& Sehnem, S. (2017). Produção da carne cunícula no Brasil como alternativa sustentável. Revista em Agronegócio e Meio Ambiente, 10(4), 1247-1270.

Brasil. Ministério da Agricultura, Pecuária e Abastecimento.Instrução Normativa $n^{\circ} 46$ de 06 de outubro de 2011. Brasília, DF, 2011. 
Brasil. Ministério da Agricultura, Pecuária e Abastecimento - MAPA. (2013). Instrução Normativa $\mathrm{n}^{\circ} 50$, de 24 de setembro de 2013. Lista de doenças de notificação obrigatória ao Serviço Veterinário Oficial. Diário Oficial [da] República Federativa do Brasil, Brasília.

Brasil. Ministério da Saúde. (2015). Doenças transmitidas por alimentos. Brasília: Ministério da Saúde. Recuperado em 20 de julho de 2020, de http:// portalsaude.saude.gov.br/index.php/o-ministerio/ principal/leia-mais-o-ministerio/653-secretaria-svs/ vigilancia-de-a-a-z/doencas-transmitidas-poralimentos-dta/11220-situacao-epidemiologica-dados

Catroxo, M. H. B., Bersano, J. G., Martins, A. M. C. P. F., Petrella, S., Portugal, M. A. S. C., \& Souza, O. S. (2009). Ultrastructural study of poxvirus causing myxomatosis in rabbits, in São Paulo and Santa Catarina, Brazil. International Journal of Morphology, 27(2)

Coelho, C. M. A. (2010). Avaliação higio-sanitária de peças de coelho-bravo (Oryctolagus cuniculus) caçadas para consumo (Dissertação de mestrado). Universidade de Trás-os-Montes e Alto Douro, Vila Real. Recuperado em 19 de novembro de 2019, de https://repositorio.utad.pt/handle/10348/555

Contreiro, J. L. M. (2014). Prevalência de Taenia pisiformis/Cysticercus pisiformis em três zonas de caça do Baixo Alentejo (Dissertação de mestrado). Universidade Lusófona de Humanidades e Tecnologias, Lisboa. Recuperado em 18 de novembro de 2019, de http://recil.grupolusofona. pt/handle/10437/5894

Del Campo, M., Brito, G., De Lima, J. S., Hernández, P., \& Montossi, F. (2010). Finishing diet, temperament and lairage time effects on carcass and meat quality traits in steers. Meat Science, 86(4), 908-914. Recuperado em 17 de novembro de 2019, de https://www.sciencedirect. com/science/article/abs/pii/S0309174010002937

Falcone, D. B., Klinger, A. C. K., \& Toledo, G. S. P. (2017). Doenças em coelhos: as 20 enfermidades que mais causam prejuízos na cunicultura revisão. Revista Brasileira de Cunicultura, 12(1). Recuperado em 18 de novembro de 2019, de http://acbc.org.br/site/images/Revis\%C3\%A3o_-Doen\%C3\%A7as_em_coelhos.pdf
Fekete, S. G., \& Kellems, R. O. (2007). Interrelationship of feeding with immunity and parasitic infection: a review. Veterinarni Medicina-Praha, 52(4), 131. Recuperado em 18 de novembro de 2019, de http://citeseerx.ist.psu. edu/viewdoc/download?doi=10.1.1.529.6951\&r $\mathrm{ep}=$ rep1\&type $=\mathrm{pdf}$

Kanayama, C. Y., Bittar, J. F., Santos, J. P. D., \& Bassi, P. B. (2011). Uso de bioterápico no controle de pasteurelose em cunicultura: relato de caso. Pesquisa Homeopática, 26(1), 3-7.

Klinger, A. C. K., Toledo, G. S. P. D., Silva, L. P. D., Maschke, F., Chimainski, M., \& Siqueira, L. (2013). Bagaço de uva como ingrediente alternativo no arraçoamento de coelhos em crescimento. Ciência Rural, 43(9), 1654-1659.

Liberman, M., Pesaro, A. E. P., Carmo, L. S., \& Serrano Junior, C. V. (2013). Calcificação vascular: fisiopatologia e implicações clínicas. Einstein (São Paulo), 11(3), 376-382. Recuperado em 20 de novembro de 2019, de https://www.scielo.br/scielo. php?pid $=$ S1679-45082013000300021\&script $=$ sci arttext

Lima, D. C. V. (2015). Ocorrência e fatores de risco associados à infecção por Toxoplasma gondii em coelhos domésticos no estado de Pernambuco, Brasil (Dissertação de mestrado). Universidade Federal Rural de Pernambuco, Recife. Recuperado em 18 de novembro de 2019, de https://app.uff. br/riuff/handle/1/6141

Lopes, A. C. S. (2010). Cristalúria em coelhos (Relatório de graduação). Universidade Técnica de Lisboa, Lisboa. Recuperado em 20 de novembro de 2019, de https://www.repository.utl.pt/ handle/10400.5/2663

Luciano, M. V. C. (2008). Manejo sanitario y enfermedades más frecuentes que afectan al conejo. Estación Experimental Agropecuaria Paraná, 1, 20.

Machado, L. C. (2012). Opinião: panorama da cunicultura brasileira. Revista Brasileira de Cunicultura, 2(1). Recuperado em 17 de novembro de 2019, de http://acbc.org.br/site/images/stories/ Panorama_da_Cunicultura_Brasileira_I.pdf

Maertens, L., \& De Groote, G. (1984). Influence of the number of fryer rabbits per cage on their 
performance. Journal of Applied Rabbit Research, 7(4), 151-153.

Makino, L. C., \& Nakaghi, L. S. O. (2008). Pasteurelose em coelhos: relato de casos. Ars Veterinaria, 21(4), 138-141. Recuperado em 19 de novembro de 2019, de http://www.arsveterinaria. org.br/index.php/ars/article/view/56

Makino, L. C., Nakaghi, L. S. O., \& Carregal, R. D. (2005). Dermatite úmida aguda ou "doença do pêlo verde" ou "papada molhada" em coelhos: relato de casos. Ars Veterinaria, 21(4), 135-137. Recuperado em: 19 de novembro de 2019, de http:// arsveterinaria.org.br/index.php/ars/article/view/55

Marques, R. A. (2014). Doença hemorrágica do coelho: mecanismos que conferem resistência ou susceptibilidade à infecção por calicivirus (Tese de doutorado). Universidade do Porto, Porto. Recuperado em 19 de novembro de 2019, de https://repositorioaberto.up.pt/bitstream/10216/84928/2/31202.pdf

Mello, H. V., \& Silva, J. F. (2003). Criação de coelhos (p. 264). Viçosa: Editora Aprenda Fácil.

Mellor, D. J., \& Reid, C. S. W. (1994). Concepts of animal well-being and predicting the impact of procedures on experimental animals. Research and Experimentation, 3-18. Recuperado em 17 de novembro de 2019, de https://animalstudiesrepository. org/exprawel/7/

Nunes, R. A. P. (2016). Relatório de Estágio Profissionalizante - Farmácia São João (Dissertação de mestrado). Faculdade de Farmácia da Universidade do Porto. Porto. Recuperado em 18 de novembro de 2019, de https://repositorioaberto.up.pt/bitstream/10216/86108/2/157822.pdf

Papeschi, C. (2010). Las enfermedades más importantes de la piel de los conejos. Cunicultura. Recuperado em 18 de novembro de 2019, de https:// cunicultura.com/2010/10/las-enfermedades-masimportantes-de-la-piel-de-los-conejos

Patrício, R. (2014). Seroprevalência de Encephalitozoon cuniculi em coelhos assintomáticos da região de Lisboa (Dissertação de mestrado). Universidade Lusófona de Humanidades e Tecnologias, Lisboa. Recuperado em 19 de novembro de 2019, de http://recil.grupolusofona. pt/handle/10437/5944
Pires, P. R. (2012). Raças da cunicultura. Técnico em agropecuária. Recuperado em 20 de julho de 2020, de https://tecnicoemagro.blogspot. com/2012/04/racas-da-cunicultura.html

Rebelo, T. S. C. (2017) Staphylococcus aureus resistente à meticilina (MRSA) como agente etiológico de lesões subcutâneas purulentas em coelhos para consumo (Oryctolagus cuniculus) (Dissertação de mestrado). Universidade de Trás-os-Montes e Alto Douro, Vila Real. Recuperado em 19 de novembro de 2019, de https://www.researchgate. net/publication/329322739_Caracterizacao_ genotipica_de_Staphylococcus_aureus_resistente_a meticilina_MRSA_como_agente_etiologico_de lesoes_subcutaneas_purulentas_em_coelhos_para consumo_Oryctolagus_cuniculus

Rodrigues, P. A. A. (2007) Cunicultura: um estudo sobre a aplicação da Contabilidade de Custos voltada aos pequenos empresários (Monografia de graduação). Pontifícia Universidade Católica de São Paulo, São Paulo. Recuperado em 17 de novembro de 2019, de http://www.coelhoecia. com.br/Zootecnia/Cunicultura\%20um\%20 Estudo\%20Sobre\%20a\%20Aplicacao\%20da\%20 Contabilidade $\% 20 \mathrm{de} \% 20$ Custos $\% 20$ Voltada $\% 20$ aos\%20Pequenos\%20Empresarios.pdf

Rosell, J., \& Madrid, N. S. (2002). Profilaxia em explorações de cunicultura intensiva. In Anais da II Jornadas Internacionais de Cunicultura. Vila Real: Associação Portuguesa dos Engenheiros Zootécnicos (APEZ). Recuperado em 20 de novembro de 2019, de http://cunivetservice.com/ docs/Profilaxia.Pt.2002.pdf

Santos, J. A. (1975). Patologia especial dos animais domesticos (mamiferos e aves). Rio de Janeiro: Instituto Interamericano de Ciências Agrícolas. Editorial IICA. Recuperado em: 19 de novembro de 2019, de https://books.google. com.br/books?hl=pt-BR\&lr=\&id=K8gOAQA AIAAJ\&oi $=$ fnd $\& p g=$ PA $7 \& d q=$ Samus,+ S. + A. + Dermatofitose + Del + Conejo, + Micoses $+\mathrm{O}+\mathrm{Ti} \%$ C3\%B1a.+Engormix,,+ Santos,,+ J.+A.+Patolog ia + especial + dos+animais + dom $\% \mathrm{C} 3 \% \mathrm{~A} 9$ sticos $+(\mathrm{mam} \% \mathrm{C} 3 \% \mathrm{ADferos}+\mathrm{e}+$ aves $) .+$ Editorial $+\mathrm{IIC}$ $\mathrm{A},+1975 . \&$ ots $=5 \mathrm{wn} 0 \mathrm{i} 3 \mathrm{KscR} \& \mathrm{sig}=\mathrm{m} 5 \mathrm{jizfsFrU}$ gR8F-UtuV3oP6cMLY\#v=onepage \&q\&f=false

Schiere, J. B., \& Corstiaensen, C. J. (2008). Criação de coelhos em quintais, nas regiões tropicais (pp. 
53-62). Wageningen: Editora CTA. Recuperado em 19 de novembro de 2019, de https://cgspace. cgiar.org/bitstream/handle/10568/64436/AD20pt. pdf? sequence $=3 \&$ isAllowed $=\mathrm{y}$

Silva, A. C., Da Silva, F. F., \& Bett, V. (2017). A prevalência de mastites em vacas leiteiras do município de Carlinda (MT). PUBVET, 11, 744839. Recuperado em 19 de novembro de 2019, de https://www.pubvet.com.br/artigo/3943/aprevalecircncia-nbspde-mastites-em-vacas-leiteirasdo-municiacutepio-de-carlinda-mt-no-ano-de-2016

Silva, M. A. J. G. (2019). Modelagem do consumo alimentar e padrões comportamentais de coelhos Nova Zelândia Branco submetidos a desafios crônicos por altas temperaturas (Dissertação de mestrado). Universidade Federal de Lavras, Lavras. Recuperado em 20 de julho de 2020, de http://177.105.2.222/bitstream/1/34934/1/ DISSERTA $\%$ c3\%87\%c3\%83O Modelagem $\% 20$ do $\% 20$ consumo $\% 20$ alimentar $\% 20 \mathrm{e} \% 20$ padr $\%$ c $3 \%$ b5es $\% 20$ comportamentais $\% 20 \mathrm{de} \% 20$ coelhos\%20Nova\%20Zel\%c3\%a2ndia\%20 Branco $\% 20$ submetidos $\% 20 \mathrm{a} \% 20$ desafios $\% 20$ cr\%c3\%b4nicos\%20por\%20altas\%20temperaturas.pdf

Simões, J. (2011). Medicina da produção - módulo leporídeos. Veterinaria.com.pt, 3(1-2), 1-48. Recuperado em: 18 de novembro de 2019, de http://www.veterinaria.com.pt/media//DIR_27001/ vcp3-1-2-e1.pdf
Souza, N. C., Baia, J. D., \& Gioso, M. A. (2016). Exodontia de incisivos em coelho (Oryctolagus cuniculus) com maloclusão dentária-Relato de caso. Revista de Educação Continuada em Medicina Veterinária e Zootecnia do CRMV-SP, 14(2), 56-56. Recuperado em 19 de novembro de 2019, de https://revistamvez-crmvsp.com.br/ index.php/recmvz/article/view/31895

Thrusfield, M. (1995). Diagnostic testing. Veterinary epidemiology, 2, 266-85.

Trapp, S. M., Iacuzio, A. I., Barca Junior, F. A., Kemper, B., Da Silva, L. C., Okano, W., Tanaka, N. M., Grecco, F. C. A. R., Cunha Filho, L. F. C., \& Stereza, F. A. M. (2010). Causas de óbito e razões para eutanásia em uma população hospitalar de cães e gatos. Brazilian Journal of Veterinary Research and Animal Science, 47(5), 395-402. Recuperado em 19 de novembro de 2019, de https:// www.revistas.usp.br/bjvras/article/view/26821

Valentim, J. K., Machado, L. C., Lopes, V. L., Luana, K., De Paula, C., Bittencourt, T. M., Rodrigues, R. F. M., Roberto, C. H. V., \& \& Dallago, G. M. (2018). Perfil dos criadores de coelho PET no Brasil. Revista Brasileira de Cunicultura, 13, 27-45. Recuperado em: 17 de novembro de 2019, de http://acbc.org.br/site/ images/Perfil_dos_cunicultores_PET.pdf 